\title{
Classification of crankshaft remanufacturing using Mahalanobis-Taguchi system
}

\author{
M.Y. Abu ${ }^{1 *}$ K.R. Jamaluddin ${ }^{2}$ and M.A. Zakaria ${ }^{1}$ \\ ${ }^{1}$ Faculty of Manufacturing Engineering, Universiti Malaysia Pahang, \\ 26600 Pekan, Pahang, Malaysia \\ *Email: myazid@ump.edu.my \\ Phone: +6094245815; Fax: +6094245888 \\ ${ }^{2}$ UTM Razak School of Engineering and Advanced Technology, \\ Universiti Teknologi Malaysia, \\ 54100 Kuala Lumpur, Malaysia
}

\begin{abstract}
Remanufacturing is a process of returning a used product to at least its original performance with a warranty that is equivalent or better than that of a newly manufactured product. During a preliminary inspection on remanufacturing companies, it was found that there is no end life for crankshafts in terms of classifying it either to remanufacture, repair or reject due to limited information provided by the original equipment manufacturer. The manufacturer did not provide any information on the annual quantity produced and their specifications to the remanufacturing company for the purpose of referencing. Eventually, the distinctiveness of the remanufactured crankshaft from the original cannot be measured. Thus, the aim of this work is to classify crankshafts' end life into recovery operations based on the Mahalanobis-Taguchi System. The crankpin diameter of six engine models were measured in order to develop a scale that represents their population in a scatter diagram. It was found that on the diagram of each engine model, the left distributions from the center point belong to rejected crankshafts, the right distributions belong to re-manufacturable crankshafts, and the upper distributions belong to the repairable crankshafts. The developed scale is believed to be able to help remanufacturers instantaneously identify and match any unknown model crankshafts to its right category. The Ministry of International Trade \& Industry (MITI) has established a remanufacturing policy under RMK11 and put in efforts to encourage Malaysians to venture into the remanufacturing business. Thus, this model will help the industry to understand and formulate their decision-making to sustain the end of life of their products.
\end{abstract}

Keywords: Remanufacturing; crankshaft; Mahalanobis Taguchi System; pattern recognition.

\section{INTRODUCTION}

In 1831, the transformation of a steam frigate into an ironclad ship [1] was the first known application of remanufacturing. Subsequently, applications on a large scale became obvious during World War II because there was no production of new cars and spare parts since all production facilities were only focused on the production of war equipment. The remanufacturing of automotive products is an effective strategy to promote sustainability in the automotive industry because when compared to new products, remanufactured products only use $50 \%$ of the cost for new products [2], utilize $60 \%$ of energy and $70 \%$ 
of materials, and create jobs for skilled workers [3]. Many researchers give the definition of remanufacturing as "replacement parts are new or remanufactured" and "testing is performed to manufacturer's specifications and original production standards". During a remanufacturing process, the product is completely dismantled through a series of industrial processes in a factory environment. Some usable components are cleaned in particular ways and subsequently stored into a component inventory. Then, those are carefully inspected against the original specifications and tested under the manufacturer's specification and original production standards [4]. This is done to increase the second user's confidence in remanufactured products and it is thought to explain why remanufactured products appear to have better reliability than new products [5].

Preliminary inspection is a part of the remanufacturing process to decide whether the crankshaft can be remanufactured or rejected before proceeding to other stages such as grinding, polishing, inspection, leak testing, final cleaning and packaging [6]. Based on current practices, the decision is made based on the tolerance provided by the original equipment manufacturer (OEM), whereby each crankshaft has its deterministic tolerance. With respect to the end of life (EOL) of crankshaft as a core, the diameter of crankpin could be either within or lower than the re-manufacturable tolerance. Several issues in pattern recognition of remanufacturing industries were found. Gavidel and Rickli [7] devoted triage as an agile sorting strategy in extreme arrival scenarios and is utilized as a complementary core sorting strategy. Tagaras and Zikopoulos [8] examined whether it was advisable to establish a sorting procedure performed either centrally or locally at the collection sites to classify errors and subsequently identify cores that are suitable for remanufacturing before disassembly. Due to the lack of clearly defined sustainability indicators which might be used in the assessment of remanufacturing activities, Golinska, Kosacka [9] provided a new tool for decision-making based on Grey's decisions to help in classifying the current state of remanufacturing operations and prioritizing operations which need improvement. With respect to disassembly for remanufacturing, Lind, Olsson [10] used a strategic approach to examine how product, process and organisational design affect disassembly strategies by grouping the factors that affect disassembly within the remanufacturing process. In addition, several important work have identified crankshaft classification. An automated diagnosis using an artificially intelligent system was proposed by [11] to monitor large diesel engines by analysing a crankshaft's angular speed variations and identifying a failure risk level at a greatest cost concern. Linear parametric classifiers were applied by [12] to diagnose misfire in internal combustion engines by using crank-angle domain digital filters to extract features from the measured engine speed signal, one of the characteristics of a misfire. A proper intelligent approach was utilized by [13-15] in a fault diagnosis of spark plugs in internal combustion engines based on acoustic and vibration signals through using sensor fusion and classifier combination. A knowledge-based approach as presented by $[16,17]$ was used to develop an inspection process based on observations of the propagation of thermal waves. It is posited as a highly reliable method for checking cracks, which is crucial for defect-free production. An algorithm for recognition of signal drop-outs developed particularly for measuring valvetrain kinematics is needed in order to save data that are not affected by a drop-out phenomenon. This will increase the throughput of an engine test stand and decrease the time needed for the evaluation of the valvetrains of combustion engines [1821]. Hosek [22] investigated the effects of piston scuffing fault on engine performance and vibrations. Acoustic emission signals through transformed wavelet packets are employed to decompose the signals into different frequency ranges in order to detect valve abnormalities in a reciprocating compressor. This method believes that valve 
problems can be identified effectively [23]. A frequency-domain method was proposed by [24] for the on-line identification of parameters describing the torsional dynamics of internal combustion engines. However, it is hard to find any previous works classifying EOL crankshafts by developing a scale with detailed explanation.

This work classifies six engine models into recovery operations such as repairable, and remanufacturable based on the Mahalanobis-Taguchi System (MTS). The method developed is a scale to indicate how far the characteristics of a signal data are from the reference sample. The classification is shown in a scatter diagram whereby the closer the tolerance to the maximum remanufacturable tolerance is, the larger the MD is generated. The developed scale is able to help remanufacturers instantaneously identify and match any unknown model crankshaft to their right category.

\section{METHODOLOGY}

The work has identified the number of crankshafts required for each engine model and their remanufacturable tolerance obtained from the remanufacturer as shown in Table 1. However, all these samples are using historical data.

Table 1. Data collection of crankshafts

\begin{tabular}{lccc}
\hline \multirow{2}{*}{ Engine model } & \multirow{2}{*}{ No. of sample } & \multicolumn{2}{c}{ Remanufacturable tolerance $(\mathrm{mm})$} \\
\cline { 3 - 4 } & & Lower limit & Upper limit \\
\hline Caterpillar & 70 & 117.000 & 117.043 \\
Detroit & 59 & 114.262 & 114.305 \\
Hatz & 60 & 111.501 & 111.520 \\
Man & 84 & 112.020 & 112.040 \\
Mtu183 & 65 & 113.980 & 114.000 \\
Perkins & 75 & 111.159 & 111.190 \\
\hline
\end{tabular}

\section{Crankshaft Classification using T Method-3}

T Method-3 is one of the MTS sub-methods for pattern recognition that is able to classify objects into a reference sample and signal data [25]. Unit data was selected based on the highest number of samples among other samples. To compute the sensitivity $\beta$, linear equation $L$ and effective divider $r$ should be calculated first as shown in Eq. (1) and Eq. (2) respectively, for each unit data.

$$
\begin{gathered}
\text { Linear equation, } L_{1}=\bar{x}_{1} x_{11}+\bar{x}_{2} x_{12}+\cdots+\bar{x}_{k} x_{1 k} \\
\text { Effective divider, } r=\bar{x}_{1}^{2}+\bar{x}_{2}^{2}+\cdots+\bar{x}_{k}^{2}
\end{gathered}
$$

Hence, the sensitivity $\beta$ as shown in Eq. (3) indicates the steepness of incline of the straight line. Ascending the line to the right indicates that the $L$ is positive, whereas descending the line to the right indicates that the $L$ is negative.

$$
\text { Sensitivity, } \beta_{1}=\frac{L_{1}}{r}
$$

To calculate the standard $\mathrm{SN}$ ratio $\eta$ for each unit data, total variation, variation of proportional term, error variation and error variance should be calculated first as shown in Eq. (4), Eq. (5), Eq. (6) and Eq. (7), respectively. 


$$
\begin{gathered}
\text { Total variation, } S_{T 1}=x_{11}^{2}+x_{12}^{2}+\cdots+x_{1 k}^{2} \\
\text { Variation of proportional term, } S_{\beta 1}=\frac{L_{1}^{2}}{r} \\
\text { Error variation, } S_{e 1}=S_{T 1}-S_{\beta 1} \\
\text { Error variance, } V_{e 1}=\frac{S_{e 1}}{k-1}
\end{gathered}
$$

Subsequently, the standard SN ratio $\eta$ is given in the following Eq. (8). The larger the value of $\eta$, the stronger the relationship between input and output.

$$
\text { SN ratio, } \eta_{1}=\frac{1}{V_{e 1}}
$$

The standard SN ratio expression is used to treat the average values of the items of the unit space as standard signals; the dividend might as well be represented by $r$ but the numeral one has been chosen because it is common to all members. Using the previously calculated sensitivity $\beta$ and standard $\mathrm{SN}$ ratio $\eta$, the two variables $\mathrm{Y}_{1}$ and $\mathrm{Y}_{2}$ can be calculated. For $\mathrm{Y}_{1}, \beta$ is used directly as shown in Eq. (9), while for $\mathrm{Y}_{2}, \beta$ will first be converted as follows to allow for an evaluation of any scatter from the standard conditions as shown in Eq. (10).

$$
\begin{gathered}
Y_{i 1}=\beta_{i} \\
Y_{i 2}=\frac{1}{\sqrt{\eta_{i}}}=\sqrt{V_{e i}}
\end{gathered}
$$

Consequently, MD can be calculated based on Eq. (11). MD always has a zero or

\begin{tabular}{|c|c|c|c|}
\hline \multirow{2}{*}{ Data no. } & \multicolumn{2}{|c|}{ Parameter } & \multirow{2}{*}{ Linear equation } \\
\hline & 2 & $\ldots$ & \\
\hline 1 & $x_{11}^{\prime} \quad x_{12}^{\prime}$ & $\ldots \quad x_{1 k}^{\prime}$ & $L_{1}^{\prime}$ \\
\hline 2 & $x_{21}^{\prime} \quad x_{22}^{\prime}$ & $\ldots \quad x_{2 k}^{\prime}$ & $L_{2}^{\prime}$ \\
\hline$\ldots$ & $\ldots$ & $\ldots \quad \ldots$ & $\ldots$ \\
\hline$l$ & $x_{l 1}^{\prime} \quad x_{l 2}^{\prime}$ & $\ldots \quad x_{l k}^{\prime}$ & $L_{l}^{\prime}$ \\
\hline
\end{tabular}
a positive value since $A$ is a non-negative definite. The larger the tolerance acquired, which is closer to the maximum remanufacturable tolerance is, the larger the MD that will be developed.

$$
\text { Mahalanobis distance, } D^{2}=\frac{Y A Y^{T}}{k}
$$

Table 2. Linear equations of signal data

Signal data can be more than one but they must have a lower number of samples compared to the unit data. In this work, the remaining 5 engine models can be defined as signal data when the number of signal data has been acquired as shown in Table 2, towards evaluating discriminating ability. All of the procedures to obtain MD for signal 
data are similar with the unit data. The only difference is that the value of effective divider $r$ belongs to the unit data.

\section{RESULTS AND DISCUSSION}

\section{Crankshaft Classification}

The main intention of the work is to classify the EOL crankshaft into categories for recovery operation which are rejected, repairable and remanufacturable. Consequently, the distinctiveness of signal data from the unit data can be seen clearly. According to Figure 1 (a), since the sample numbers of remanufacturable (35) and rejected (35) crankpin diameters are equal, the distribution of samples inside the scatter diagram is quite stable for both regions. By using the center point of samples at coordinate (1.0444, 0.01466), the classification on the right distribution belongs to the remanufacturable group, while the left distribution belongs to the rejected group. Thus, the threshold is between 774002.21 to 798279.92 with the average of 787586 , which is far from the unit data. Meanwhile, any unknown sample which falls within this threshold is considered to be of the Caterpillar engine model. In Figure 1 (b), since the sample number of remanufacturable crankpins are greater than the rejected and repairable groups, the distribution of samples inside the scatter diagram is dense on the right. From the center point of the coordinate $(1.020033,0.016551)$, the right distribution belongs to the remanufacturable group, whereas the left distribution belongs to the rejected group. The distribution above the center point actually belongs to the repairable group, which consists of a mixture between remanufacturable and rejected samples. Thus, the threshold is between 153277.39 to 164993.55 with an average of 160844.42 , which is closer to the unit data. Any unknown sample which falls outside this threshold cannot be labeled as the Detroit engine model. In Figure 1 (c), the distribution of samples is dense on the left since the number of rejected crankshafts are larger with 39 samples than those of the remanufacturable and repairable crankshafts. Thus, the threshold for the Hatz engine model is between 8267.17 to 10165.71 , which is far from the unit data. According to Figure 1 (d), although the distribution of samples is quite fair because the sample numbers of remanufacturable (40) and repairable (44) crankpin diameters are approximately equal, the threshold for the Man engine model is between 0.092534 to 7.446333, which is the unit data in this crankshaft classification. The threshold for the Mtu183 engine model is between 116734.84 to 123173.90 , while the threshold for the Perkins engine model is between 22540.533 to 26192.208 as shown in Figure 1 (e) and Figure 1 (f) respectively.

\section{Combination of Scatter Diagrams}

The larger the value of tolerance, which is closer to the maximum remanufacturable tolerance, the larger the MD developed. However, due to the maximum remanufacturable tolerance that it can achieve, it has a dependency on MD which can develop as well. Furthermore, it is impossible for the acquired remanufacturable tolerance to be more than that provided by OEM because the surface of the crankpin must eventually be subjected to wear and tear as a result of the conversion process from a reciprocating motion into a rotary motion $[26,27]$. The relationship between acquired remanufacturable tolerance and MD is proven by taking into consideration the value of sensitivity, $\beta$ for each engine model as shown in Figure 2. 


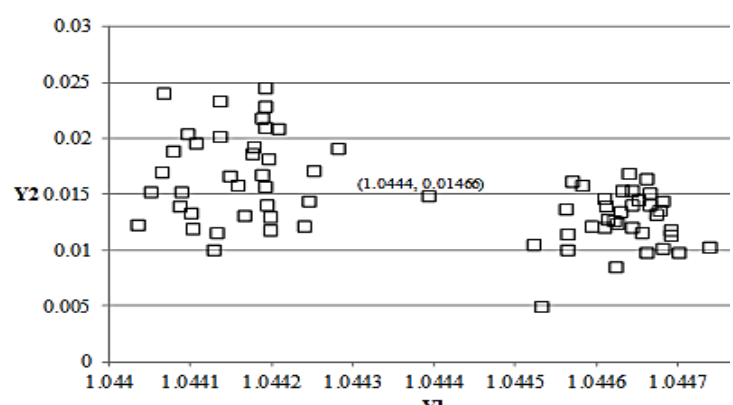

(a)

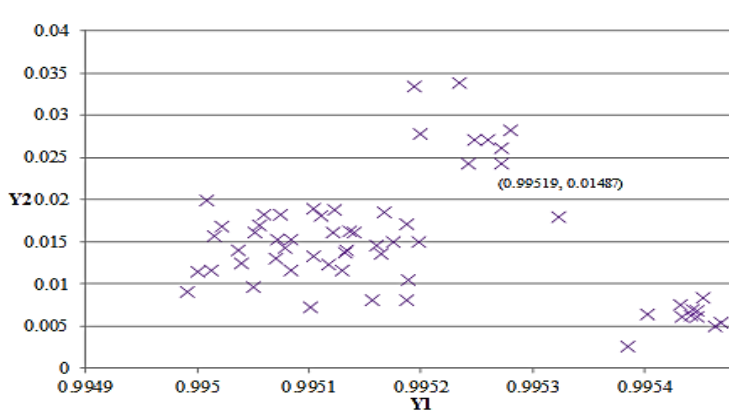

(c

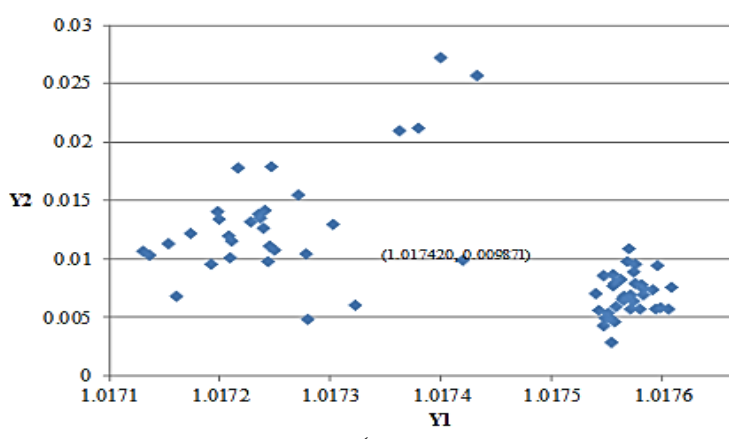

$(\mathrm{e}$

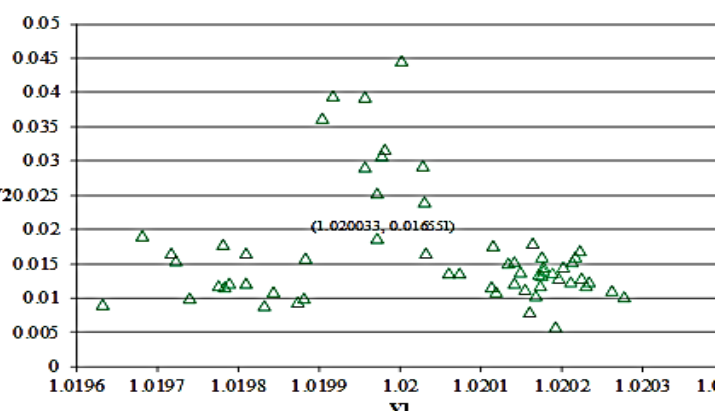

(b)

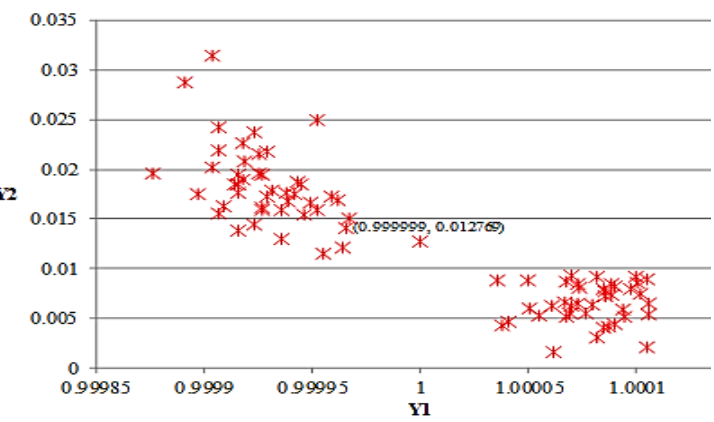

(d)

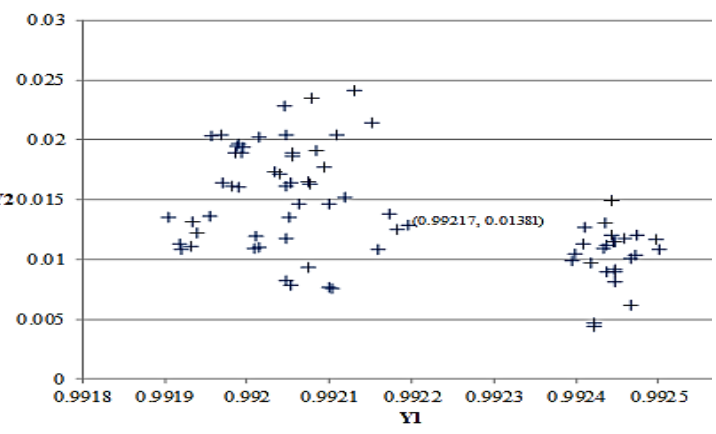

(f)

Figure 1. Scatter diagram of (a) Caterpillar, (b) Detroit, (c) Hatz, (d) Man, (e) Mtu183 and (f) Perkins engine models

By considering only the remanufacturable samples for each engine model, all those figures have a positive value of sensitivity. It means that the plotting or distribution on the scatter diagram must ascend from the left to the right as shown in Figure 2 (a), (b), (d) and (e). However, the Hatz and Perkins engine models' graphs descend as shown in Figure 2 (c) and (f) because the Man engine model acts as a reference sample and plays a major role as a mirror. The isolated crankshaft classifications among the six engine models in the scatter diagram now appear reasonable and are more convincing. Therefore, by combining all the scatter diagrams into a single view as shown in Figure 3, a distinctive crankshaft pattern through their tolerance among them is observed. It is found that any unknown sample, either rejected, repairable or remanufacturable can easily be classified by remanufacturers for better identification and documentation. 


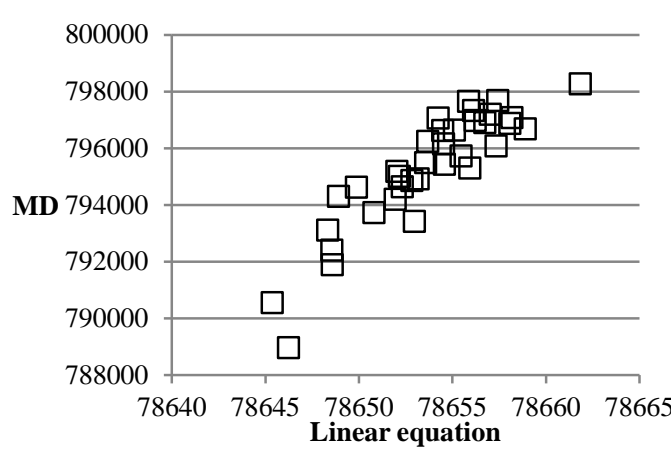

(a)

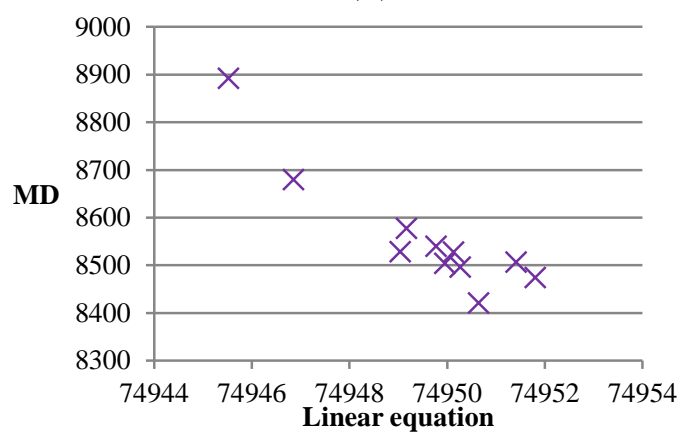

(c)

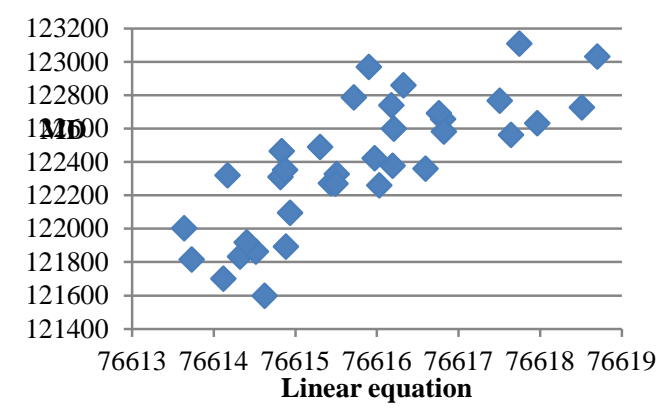

Figure 2. Relationship between remanufacturable tolerance and $(\mathrm{f}) \mathrm{HD}$ for (a) Caterpillar,

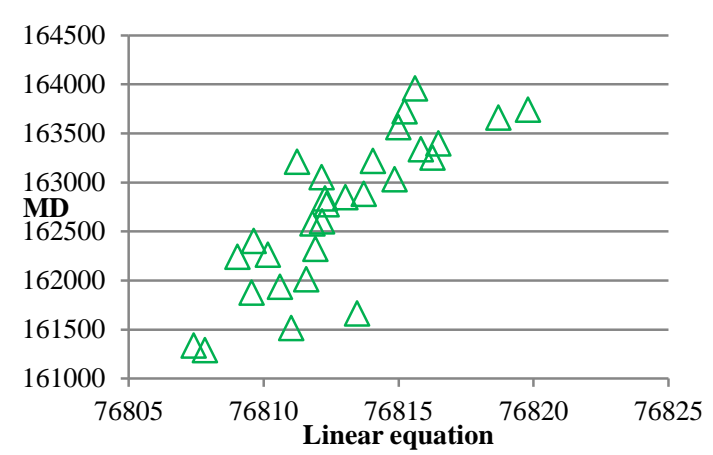

(b)

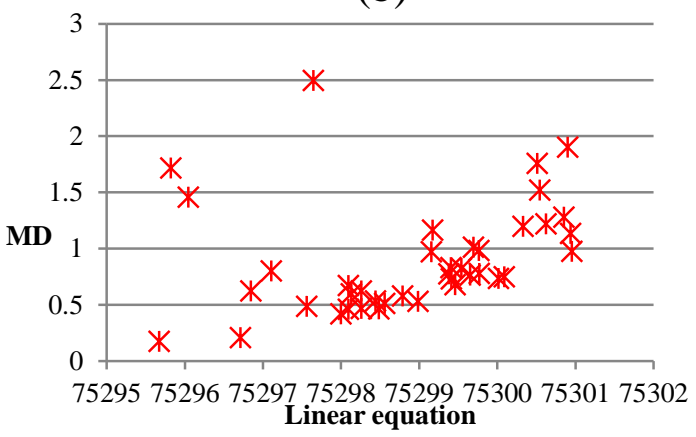

(d)

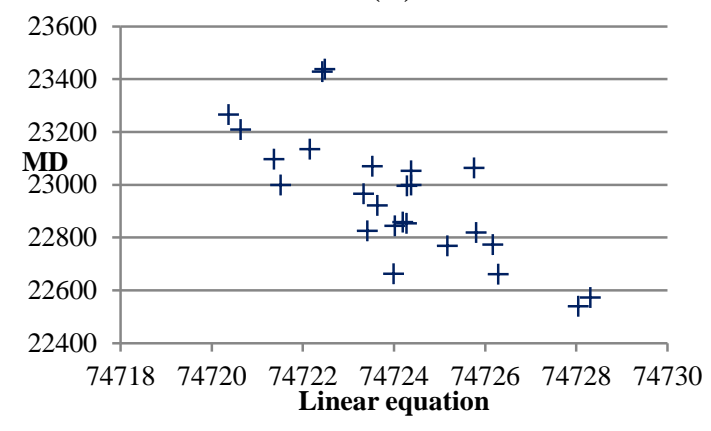

Figure 2. Relationship between remanufacturable tolerance and $\mathrm{f}$ ( $)$ D for (a) Caterpillar, (b) Detroit, (c) Hatz, (d) Man, (e) Mtu183 and (f) Perkins

\section{Predicting the Conditions using Unknown Data}

The work has transformed these thresholds into single lines as shown in Figure 4. The Man engine model is the unit data or the centre of any threshold. However, the threshold of the remanufacturable samples overlap with the repairable samples because all 40 remanufacturable samples have lower linear equation values, thus producing a lower MD value which eventually falls into the repairable threshold. Obviously, the Caterpillar engine has a separate threshold between its rejected and remanufacturable samples, similarly to the Perkins's threshold, but both are in the opposite manner. Referring to Figure 3, Caterpillar's classification is on the right distribution while Perkins is on the left distribution. Referring to Figure 1, the pattern is clear: the rejected samples are on the left distribution while the remanufacturable samples are on the right distribution. By combining these fundamentals similarly to the Hatz's threshold, the Detroit and Mtu183 engines have similar positions on the right distribution to the reference as shown in Figure 3. All of the remanufacturable samples have lower linear equation values, thus producing a lower MD value which eventually falls into the repairable threshold. 


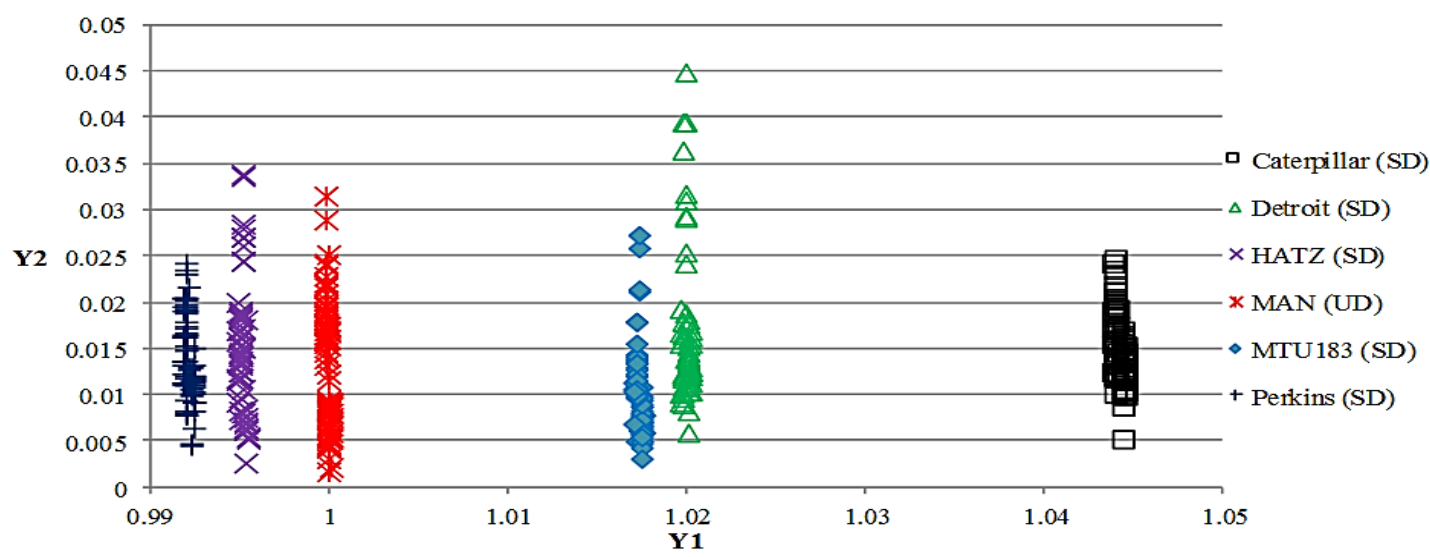

Figure 3. Crankshaft classification with all engine models.

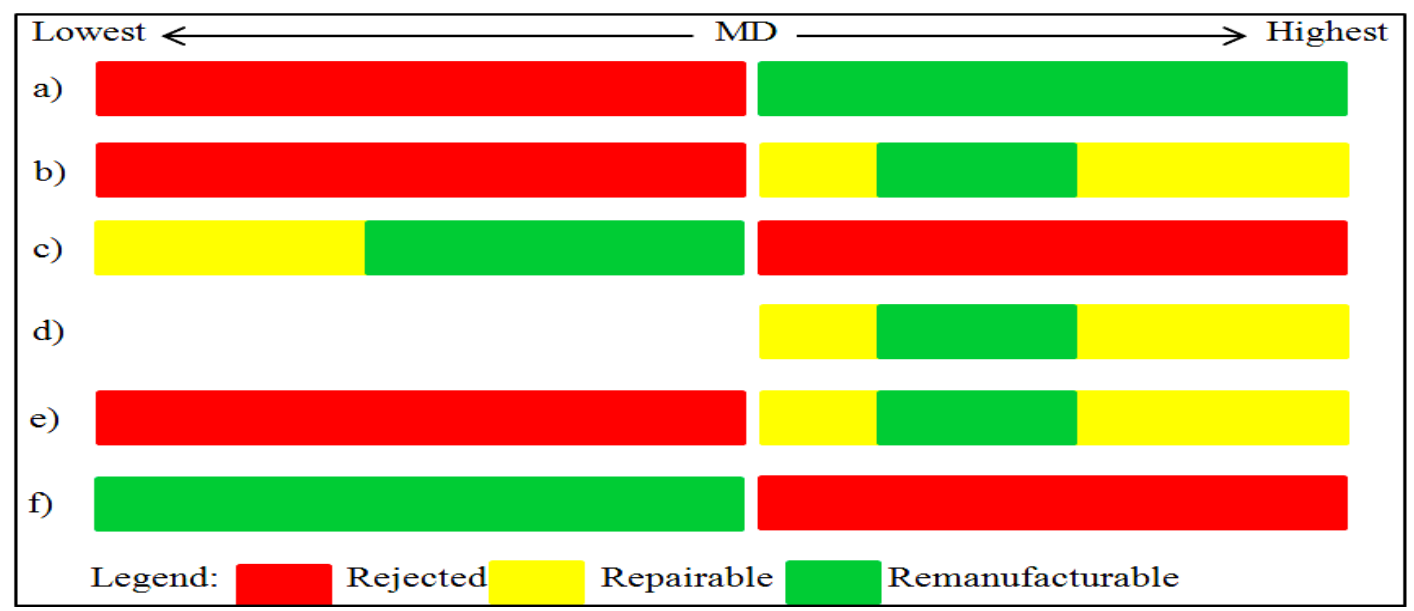

Figure 4. Thresholds of (a) Caterpillar, (b) Detroit, (c) Hatz, (d) Man, (e) Mtu183 and (f) Perkins.

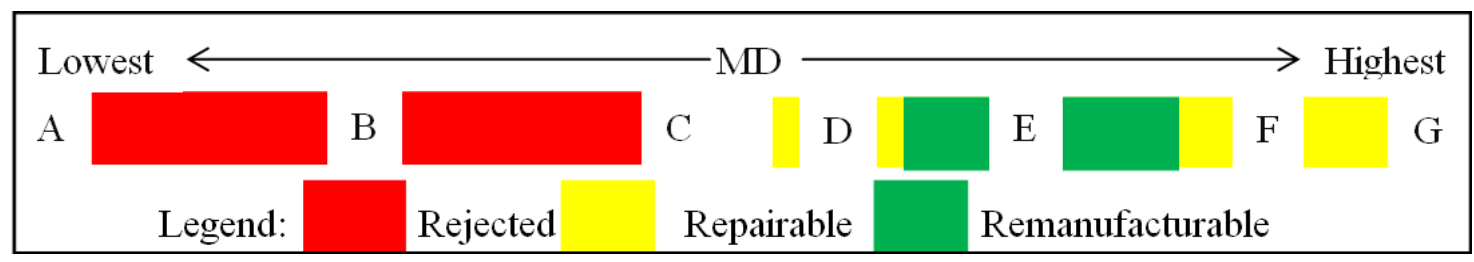

Figure 5. Predicting the condition of unknown data

The work was able to predict the condition of unknown data at different positions such as A, B, C, D, E, F and G using an example of the Detroit engine as shown in Figure 5. Any unknown sample which falls at point $A, B$ and $C$ is not within the Detroit's threshold, thus is obviously rejected because the linear equation value is low. Any unknown data that falls at point $\mathrm{D}$ and $\mathrm{F}$ can be categorized either as repaired or rejected as some are within the Detroit engine's threshold while some are not. Unknown data which falls at point $E$ is within the Detroit's threshold and is obviously remanufacturable. Finally, unknown data which falls at point $G$ is not within the Detroit engine's threshold because it might belong to other engine models. 


\section{CONCLUSIONS}

This work has successfully classified EOL crankshafts into their recovery operation categories such as rejected, repairable and remanufacturable. It was found that on the scatter diagram, the left distributions from the centre point belong to rejected crankshafts, the right distributions are remanufacturable and the upper distributions are repairable. This strongly helps the industry to formulate their decision-making as the remanufacturing industry needs to sustain their EOL products. It also has proven that MTS can be applied in pattern recognition problems with other well established methods. Future work is needed in order to consider significant factors during the remanufacturing process and proposing a new method to estimate remanufacturing costs for better decision-making.

\section{ACKNOWLEDGEMENTS}

The authors would like to be obliged to Universiti Malaysia Pahang for providing financial assistance under project no. RDU161101 and was partially supported by Universiti Teknologi Malaysia.

\section{REFERENCES}

[1] Technology RIo. Remanufacturing Industry Timeline. Eastman Building 01-2309 1 Lomb Memorial Drive. Rochester, NY Rochester Institute of Technology; 2006.

[2] Kumar V, Sutherland JW. Sustainability of the automotive recycling infrastructure: review of current research and identification of future challenges. International Journal of Sustainable Manufacturing. 2008;1:145-67.

[3] Charter M, Gray C. Remanufacturing and product design. International Journal of Product Development. 2008;6:375-92.

[4] Zhang T, Chu J, Wang X, Liu X, Cui P. Development pattern and enhancing system of automotive components remanufacturing industry in China. Resources, Conservation and Recycling. 2011;55:613-22.

[5] Brent AC, Steinhilper R. Opportunities for remanufactured electronic products from developing countries: hypotheses to characterise the perspectives of a global remanufacturing industry. AFRICON, 2004 7th AFRICON Conference in Africa: IEEE; 2004. p. 891-6.

[6] Lee HB, Cho NW, Hong YS. A hierarchical end-of-life decision model for determining the economic levels of remanufacturing and disassembly under environmental regulations. Journal of Cleaner Production. 2010;18:1276-83.

[7] Gavidel SZ, Rickli J. Triage as a core sorting strategy in extreme core arrival scenarios. Journal of Remanufacturing. 2015;5:1.

[8] Tagaras G, Zikopoulos C. Optimal location and value of timely sorting of used items in a remanufacturing supply chain with multiple collection sites. International Journal of Production Economics. 2008;115:424-32.

[9] Golinska P, Kosacka M, Mierzwiak R, Werner-Lewandowska K. Grey decision making as a tool for the classification of the sustainability level of remanufacturing companies. Journal of Cleaner Production. 2015;105:28-40.

[10] Lind S, Olsson D, Sundin E. Exploring inter-organizational relationships in automotive component remanufacturing. Journal of Remanufacturing. 2014;4:1. 
[11] Desbazeille M, Randall R, Guillet F, El Badaoui M, Hoisnard C. Model-based diagnosis of large diesel engines based on angular speed variations of the crankshaft. Mechanical Systems and Signal Processing. 2010;24:1529-41.

[12] Villanueva JB, Espadafor FJ, Cruz-Peragon F, García MT. A methodology for cracks identification in large crankshafts. Mechanical systems and signal processing. 2011;25:3168-85.

[13] Osburn AW, Kostek TM, Franchek MA. Residual generation and statistical pattern recognition for engine misfire diagnostics. Mechanical systems and signal processing. 2006;20:2232-58.

[14] Srihari PV, Govindarajulu K, Ramachandra K. A method to improve reliability of gearbox fault detection with artificial neural networks. International Journal of Automotive and Mechanical Engineering. 2010;2:221-30.

[15] Hafizi ZM, Epaarachchi J, Lau KT. An investigation of acoustic emission signal attenuation for monitoring of progressive failure in fiberglass reinforced composite laminates. International Journal of Automotive and Mechanical Engineering. 2013;8:1442-56.

[16] Moosavian A, Khazaee M, Najafi G, Kettner M, Mamat R. Spark plug fault recognition based on sensor fusion and classifier combination using DempsterShafer evidence theory. Applied Acoustics. 2015;93:120-9.

[17] Mansor MA, Ohsato A, Sulaiman S. Knowledge Management for maintenance activities in the manufacturing sector. International Journal of Automotive and Mechanical Engineering. 2012;5:612-21.

[18] Ghidoni S, Antonello M, Nanni L, Menegatti E. A thermographic visual inspection system for crack detection in metal parts exploiting a robotic workcell. Robotics and Autonomous Systems. 2015;74:351-9.

[19] Ramasamy D, Zainal Z, Kadirgama K, Briggs HW-G. Effect of dissimilar valve lift on a bi-fuel CNG engine operation. Energy. 2016;112:509-19.

[20] Ab Rashid MFF, Nik Mohamed NMZ, Mohd Rose AN, Kor KY. Simulation study of a vehicle production line for productivity improvement. Journal of Mechanical Engineering and Sciences. 2015;8:1283-92.

[21] Andrew-Munot M, Ibrahim RN. Remanufacturing process and its challenges. Journal of Mechanical Engineering and Sciences. 2013;4:488-95.

[22] Hosek P. Algorithm for signal drop-out recognition in IC engine valve kinematics signal measured by laser Doppler vibrometer. Optics \& Laser Technology. 2012;44:1101-12.

[23] Moosavian A, Najafi G, Ghobadian B, Mirsalim M, Jafari SM, Sharghi P. Piston scuffing fault and its identification in an IC engine by vibration analysis. Applied Acoustics. 2016;102:40-8.

[24] Sim H, Ramli R, Saifizul A, Abdullah M. Empirical investigation of acoustic emission signals for valve failure identification by using statistical method. Measurement. 2014;58:165-74.

[25] Östman F, Toivonen HT. Torsional system parameter identification of internal combustion engines under normal operation. Mechanical Systems and Signal Processing. 2011;25:1146-58.

[26] Teshima S. Quality Recognition \& Prediction: Smarter pattern technology with the Mahalanobis-Taguchi System: Momentum Press; 2012.

[27] Fonte M, Duarte P, Anes V, Freitas M, Reis L. On the assessment of fatigue life of marine diesel engine crankshafts. Engineering Failure Analysis. 2015;56:51- 